\title{
Acquisition of Letter Naming Knowledge, Phonological Awareness, and Spelling Knowledge of Kindergarten Children at Risk for Learning to Read
}

\author{
David D. Paige $\mathbb{D D}^{1}{ }^{1}$ William H. Rupley $\mathbb{D}^{2},{ }^{2}$ Grant S. Smith $\mathbb{D}^{1}{ }^{1}$ \\ Crystal Olinger $\left(\mathbb{D},{ }^{1}\right.$ and Mary Leslie ${ }^{1}$ \\ ${ }^{1}$ Bellarmine University, Louisville, KY, USA \\ ${ }^{2}$ Texas A\&M University, College Station, TX, USA \\ Correspondence should be addressed to William H. Rupley; w-rupley@tamu.edu
}

Received 29 October 2017; Revised 16 January 2018; Accepted 29 January 2018; Published 28 March 2018

Academic Editor: Olga Capirci

Copyright (C) 2018 David D. Paige et al. This is an open access article distributed under the Creative Commons Attribution License, which permits unrestricted use, distribution, and reproduction in any medium, provided the original work is properly cited.

This study measures letter naming, phonological awareness, and spelling knowledge in 2,100 kindergarten students attending 63 schools within a large, urban school district. Students were assessed across December, February, and May of the kindergarten year. Results found that, by May, 71.8\% of students had attained full letter naming knowledge. Phonological awareness emerged more slowly with $48 \%$ of students able to reliably segment and blend phonemes in words. Spelling development, a measure of phonics knowledge, found that, by May, $71.8 \%$ of students were in the partial-alphabetic phase. A series of regression analyses revealed that by the end of kindergarten both letter naming and phonological awareness were significant predictors of spelling knowledge $(b=$ .332 and .518 for LK and PA, resp.), explaining $52.7 \%$ of the variance.

\section{Introduction}

Becoming a competent reader is critical to academic achievement [1]. However, the National Assessment of Educational Progress (NAEP) reports $74 \%$ of fourth-grade students attending the nation's largest school districts score below the proficient level in reading with this percentage climbing to $83 \%$ for African-American children [2]. Unfortunately, the same data finds that a percentage of those struggling with reading in fourth grade continue to struggle through the secondary grades. This strongly suggests that students must acquire the foundational literacy skills prior to fourth grade that will set them on track for appropriate reading development. The purpose of the present study is to investigate the growth of reading subskills in approximately 2,000 kindergarten children attending a large urban district where an emphasis has been placed on the teaching of letter naming knowledge, phonological awareness, and lettersound correspondence in kindergarten.
1.1. Theoretical Framework. The verbal efficiency theory and related lexical quality hypothesis [3-6], as well as the connectionist model of reading [7], make the case that to be a successful reader phonological, orthographic, and semantic representations must be efficiently integrated. Perfetti maintains that of the various subskills involved in the reading process, fast recognition of letters and the letter-sound combinations found within words can be trained to a high level. It follows then that mastery of letter name knowledge, the ability to isolate and manipulate phonemes, and explicit instruction in letter-sound correspondence will predict conventional reading and spelling.

1.2. Letter Name Knowledge. Many kindergarten children who come from disadvantaged backgrounds often enter formal schooling lagging behind others in their early literacy development. As a result, they are at risk for later reading difficulties [8]. Research syntheses [9] have found that success in early literacy subskills such as letter naming knowledge and 
phonological awareness requires explicit instruction. That may be essential to closing the early literacy development gap.

Children lacking competent alphabet knowledge upon entry into kindergarten need explicit instruction focused on letter identity, letter naming, and writing of letters. These capabilities enable them to successfully transition into letter sounds and spellings [10]. Letter naming knowledge (LNK) requires children to master the recognition of upper- and lowercase shapes of each of the 26 graphemes of the alphabet and is a landmark accomplishment for successful reading acquisition [11, 12]. Further support for the importance of LNK is a long line of research that advances the idea of causality for letter name knowledge to more rapid learning of sounds associated with letters and letter combinations [1316]. As LNK acquisition typically occurs before phonemic awareness [17], it is critical that the child makes the connection that printed letters represent the sounds in speech, a concept called the alphabetic principle $[18,19]$. In addition to automaticity in pronouncing letter names, LNK has been reported to provide access to phonemic knowledge about the letter when in the initial or final positions of words [15, 20,21].

Critical to LNK is the ability to identify the features of letters that distinguish them from each other. Those who automatically retrieve both upper and lowercase letters from long-term memory are less likely to make letter identification errors and misread fewer words, making LNK an important predictor of a child's success with various literacy tasks [2224]. LNK has also been found to be important to early encoding processes developed through invented spelling instruction [25-29]. It is thought that this skill may tap the same central processes that facilitate reading fluency and predict reading achievement [30,31]. An example of the importance of LNK is found in a study by Share et al. [32]. The authors measured 39 variables in beginning kindergarten students including IQ, socioeconomic status, and vocabulary knowledge with results showing letter naming knowledge to be the best predictor of individual end-of-year reading achievement and the second-best predictor behind phonemic awareness of first-grade reading scores.

Additional insight into the role of letter naming is found in its relationship to spelling development. Models of developmental spelling have identified the letter naming stage as the one where the reader relies on LNK to identify words [33, 34]. Reliance on consonant names in this stage is due to the early reader's difficulty with disentangling syllables and rimes into individual phonemes. As children develop the ability to segment rimes into phonemes, they become less reliant on LNK. As such, LNK contributes to the child's accuracy with consonant identification and allows the emergence of spelling knowledge that is based on sound, although they may still be unaware of sound at the phoneme level. This suggests the transition of reading and spelling away from a visual-cue strategy to one using phonetic cues.

1.3. Phonological Awareness. An individual has phonological awareness when they are aware that words have constituent sounds and that those sounds do not always hold meaning within a word $[35,36]$. While research discussions have involved whether phonological awareness is composed of one or two constructs [37], it is now thought to be a unitary construct [38-41]. Phonological awareness develops on a continuum that moves from large to increasingly smaller units of sounds within words. This awareness ends with the identification of phonemes, the smallest unit of sound in the English language. This makes phonemic awareness a subset of phonological awareness and is present in the individual when they can isolate and manipulate individual sounds within words [37, 40]. Emergent readers acquire phonological awareness through instruction in a fairly predictable manner that begins at the syllable level, progresses to the recognition of onset and rimes (as in $c$-at), and ends with the awareness of phonemes as in $/ \mathrm{c} / / \mathrm{a} / / \mathrm{t} /$ [42]. While some evidence suggests that phonological awareness may not be required for letter-sound acquisition [13], it is clear that phonological awareness and its subcomponent phonemic awareness are an important predictor of learning to read and spell words [11, 37, 43-46].

Adams [11] uses five levels to describe the developmental progression of phonological awareness. The first begins with hearing the sounds of words, followed by the ability to compare and contrast like-sounding words in what is called the oddity task. For example, the teacher might ask the student "Which word sounds different? / cat/, / mat/, or / dog/?" The third dimension is the awareness that words can be split into syllables (to-day) and then blended back together. The fourth is the ability to split words into phonemes and put them back into a word (/dog/ into /d/ /o/ /g/ and then back to $/ \mathrm{dog} /$ ). The fifth and final dimension is the most difficult, to isolate a phoneme within a word, delete it, and then replace it with another phoneme to form a new word. Schatschneider et al. [39] add a sixth dimension where children develop sensitivity to alliteration, the ability to identify the beginning of words.

1.4. Spelling Knowledge. Following the seminal study of Read [28], researchers have clearly established that readers acquire spelling knowledge along a developmental continuum [4752]. Invented spelling occurs when one uses their selfdirected attempt to write words using print [28]. As their reading development progresses, the student uses the knowledge of phonology and orthography to write increasingly accurate word spellings. Evidence suggests that invented spelling may be an independent predictor of literacy outcomes [26]. Because the same lexical system is used in both reading and spelling [53], readers apply their orthographic knowledge to both tasks [54]. Consequently, analyzing students' spelling gives insight into their orthographic knowledge and their understanding of reading [48-50]. However, the contribution of these processes to effective spelling is not equal as when children grow in their spelling knowledge they shift their reliance from phonological to orthographic and morphological information [34, 48, 55-59].

Henderson [24] has identified five stages that he labeled preliterate, letter name, within-word, syllable juncture, and derivational constancy. The stages are described by Henderson and Templeton [60] where the preliterate stage finds that children may scribble freely and attempt to match certain sounds with marks. In the letter name stage children attempt to spell alphabetically by matching letters to sounds. As 
they acquire an increasing inventory of sight words spellings become more accurate as the child learns to examine words systematically around specific, salient features. Students in this stage are recognizing initial and final consonants, blends, and diagraphs, short vowels, affricates, and final consonant blends and diagraphs. In the early within-word stage students can provide the correct representation of short vowels, including words containing both a sounded and silent vowel (e.g., "take"). Also in this stage students are beginning to read silently. Cognitively, this stage is a large leap forward as students move from letter-to-letter analysis to reading units or groups of letters. In the syllable juncture stage students learn more complex letter features including consonant doubling, e-drops for ed and ing, and r-controlled vowels. The final stage, derivational constancy, consists of silent and sounded consonants and Latin-derived suffixes and prefixes. Understanding and mastering these various combinations of developmental spelling patterns suggests the phonological and orthographic knowledge acquired by the reader which has been shown to be related to becoming a fluent reader [61].

1.5. Learning to Read. In learning to read we ask children to match sounds to letters to learn graphophonemic relationships. This skill builds a foundation that is helpful as children learn to recognize letter patterns repeated across words [62]. When encountering sounds in a word, readers can tap their knowledge of letter-sound correspondences to identify letters and letter combinations [63]. It is not surprising then that children who are taught to segment words into their phonological parts acquire word reading skills at a faster pace than do children without these skills [32]. Additionally, the effect of phonological training has recently been found to continue through elementary school and into the sixth grade, with effects extending to ninth-grade comprehension [64]. In a study assessing the direct instruction of phonemic awareness and letter-sound knowledge, these two skills were found to fully mediate differences in word-level reading skills some five months later, thus establishing a causal connection between the two [65]. Caravolas et al. [66] found that across four languages LSK and phonemic awareness were the strongest predictors of early reading skill over a 10-month period.

1.6. The Present Study. Research has established that letter naming knowledge and phonemic awareness facilitate the learning of letter-sound correspondences. Of importance is that these two skills must be explicitly taught to students. Of interest in the present study is the extent to which this skills become evident in kindergarten students attending school within a large, urban district and from backgrounds that put many of them at risk for reading acquisition. Our interest is to study the emergence and relationships between letter identification, phonological awareness, and spelling development in kindergarten students. Our research questions are as follows:

(1) What is the extent of letter identification knowledge, phonological awareness, and spelling knowledge acquisition in kindergarten students across the latter half of the school year?
(2) To what extent do letter identification knowledge and phonological awareness predict spelling ability in kindergarten children?

\section{Method}

2.1. Context and Participants. This study is set within a large urban school district in the Midwestern United States where a multiyear, district-university partnership to improve K3 reading instruction and student reading outcomes has been underway. At the time of the study the partnership was in its third year and involved approximately $600 \mathrm{~K}-3$ teachers from 64 elementary schools. The average years of teaching experience for participant equal 11.5 (4.53). Teachers volunteer to participate in the project and receive 90 hours of classroom training in reading instruction over the course of one year. Teachers attend 14 graduate classes per semester $(28$ over the school year) where among other topics the training includes assessment and teaching of phonological awareness and the explicit teaching of letter-feature correspondence. Of the elementary students attending these 63 schools, $74.3 \%$ receive free or reduced-price lunch. A total of $46.9 \%$ are African-American, 33.2\% are Caucasian, $12.4 \%$ are Hispanic, and $7.5 \%$ are one of several other ethnicities. Male students comprise $50.2 \%$ of all students while $49.8 \%$ are female. The student sample attending the study schools comes from 46 US census tracks where the mean percent of residents living in poverty is $43.3 \%$ and varies between a high value of $86.7 \%$ and a low value of $22.5 \%$, with a median percent equal to $44.2 \%$.

The study sample consists of $n=2,100$ kindergarten students instructed by the 91 teachers participating in the improvement project. The intention was to include every student instructed by each of the participating teachers in the study sample. Due to issues such as student mobility and students not available during the assessment window, not every student is included in the sample. The mean age of students at the time of the December assessment was 5 years and 8 months while the mean age in the spring (May) was 6 years and 1 month.

2.1.1. Letter Naming Knowledge. To determine the ability to read aloud the letters of the alphabet, students are asked to complete a test of letter naming knowledge (LNK) by reading aloud 26 letters in both lower- and uppercase form. The lowercase letters "a" and "g" are provided in two different scripts, accounting for a total of 28 lowercase letters for a total of 54 letters. To begin the child is provided with a sheet with the 26 uppercase letters printed in random order. With no assistance from the teacher the child then reads aloud each letter from left to right. While the child is reading the teacher records any letters read incorrectly or omitted by the student. After the uppercase letters are read the student is then provided with a sheet containing 28 letters written in lowercase form. These letters are also arranged in a random order on the page. Again, without teacher assistance, the student reads aloud each letter while the teacher records misread and omitted words. The student's score is the number of letters out of 54 that were read correctly. An assessment of reliability found high reliability where Cronbach's $\alpha=.852$. 
2.1.2. Phonological Awareness. Students were assessed individually for phonological awareness using the Phonological Awareness Test (PAT) from the Classroom Reading Inventory [67]. The PAT is an informal, 77-item, individually administered assessment containing three subtests. The first subtest assesses the ability of the student to identify initial consonant sounds (IC) with a range of correct answers from 0 to 10. The phoneme segmentation test (PST) has a range from 0 to 15 and assesses one's ability to segment a word into its constituent sounds. The blending sounds test (BST) has a range from 0 to 55 and asks the student to combine or blend individual sounds to make a complete word. Because of the length of the blending sounds test the number of test items was reduced to 30 . This resulted in an assessment where the total number of items equaled 55. To score the PAT the student is awarded 1 point for each item completed correctly. Reliability was assessed using Cronbach's $\alpha$ and resulted in $\alpha=.820$.

2.1.3. Spelling Knowledge. The Kindergarten Inventory of Developmental Spelling (KIDS) [68] is a 5-word spelling test designed to measure the child's knowledge of letter-sound correspondences. The assessment consists of five consonantvowel-consonant (CVC) words such as jam, rob, and let. The assessment can be administered individually or to groups of students using paper and pencil. Administration begins with the teacher modeling an example word on the board such as /map/ using a think-aloud strategy. The teacher demonstrates how to stretch out or rubber band the example word to better hear the individual sounds within the word. The teacher then writes the letter corresponding to each sound in the word. Following this demonstration, the teacher then pronounces aloud the first word, followed by a sentence using the word, after which the teacher pronounces the word again. For example, the teacher would say "Jam. I had jam on my toast. Jam." Students respond by writing the word on their paper. No further modeling is provided by teacher beyond the initial example. This procedure is repeated for the remaining four words. To determine a score each of the five words is graded on a scale ranging from 0 to 6 with specific directions provided by the test author. A score of 0 would reflect a word written using scribbles, waves, or letter-like symbols. 1 indicates the use of random letters to spell the word. To earn a score of 2 the student must spell the ending consonant correctly or use an acceptable alternate identified by the author such as a P instead of a B in the word / rob/. The student must also use any random letters for the other two sounds. To earn 3 the student must use the correct beginning consonant (or an acceptable substitute) and include any random letters for the vowel and ending consonant. To earn a score of 4 the student must write the correct beginning and ending consonants (or an acceptable substitute). A score of 5 reflects the correct beginning consonant, vowel, and ending consonant (or the acceptable letter substitute). A score of 6 reflects the correct spelling of the word. To assess test reliability Cronbach's alpha was conducted and resulted in $\alpha=.91$.

2.2. Assessment Administration. As part of their 90 hours of classroom training, teachers were taught to administer
TABLE 1: Means and standard deviations of the measured variables.

\begin{tabular}{lccc}
\hline Variable & December & February & May \\
\hline Letter identification & $46.26(13.02)$ & $50.20(9.06)$ & $51.91(6.63)$ \\
Phonological awareness & $28.95(18.13)$ & $32.08(20.13)$ & $43.61(14.18)$ \\
Spelling knowledge & $4.50(9.79)$ & $10.83(11.47)$ & $25.05(6.86)$ \\
\hline
\end{tabular}

assessments for letter naming knowledge (LNK), phonological awareness, and spelling knowledge. Training consisted of an explanation of each assessment including what subskill it measured and the protocol for its administration. Teachers then practiced administering each assessment with a classroom peer under the guidance of the instructor. During the following two weeks teachers were observed by a literacy coach experienced in the administration of each assessment while they assessed two students in their classroom. Literacy coaches used a Likert-scaled rubric to grade the teacher on the administration of each assessment. These rubrics were then reviewed by the class instructor to insure the quality of administration. In cases where required benchmarks were not achieved, the teacher was remediated by the instructor and reevaluated for fidelity by the literacy coach.

Because letter naming, phonological awareness, and spelling knowledge are learned through instruction, we did not measure these skills during the first few months of the school year. Our first measurement period took place in December in order to give time for children to benefit from instruction. Our second and third measurement periods occurred in February and May. During each of the three administration periods teachers were given three weeks to assess the students in their class. Teachers then submitted the scores for their students through transmission of an Excel spreadsheet to a school-wide literacy coach. Coaches had also been trained on all assessment instruments and provided instruction by the researchers on insuring teachers reported their data correctly. Data was submitted to the research team by the coaches for each school. In instances where data questions arose, coaches confirmed test results with the teacher in question.

\section{Results}

Means for the measured variables are shown in Table 1 while the bivariate correlations are in Table 2. Letter naming knowledge (LNK) means reveal the majority of growth had occurred by December with slower growth coming in February and May. Both phonological awareness (PA) and spelling knowledge (SK) showed the strongest growth between February and May. Bivariate correlations for December reveal a moderate correlation (.491) between LNK and PA while the correlation with SL is very small (.084). By February the correlation between all variables was similarly moderate, while in May correlations had strengthened to .432 between LNK and PA and to .556 between PA and SK. For letter naming knowledge (LNK) December period reveals a mean of 46.26; however, Figure 1 shows only $35.9 \%$ of students had mastered all 54 letters. In February, the mean grew to 50.20 while $56.1 \%$ of students knew all letters, and by 
TABLE 2: Bivariate correlations of the measured variables.

\begin{tabular}{|c|c|c|c|c|c|c|c|c|c|}
\hline Variable & (1) & $(2)$ & (3) & $(4)$ & $(5)$ & $(6)$ & $(7)$ & $(8)$ & (9) \\
\hline (1) December LNK & 1 & & & & & & & & \\
\hline (2) December PA & .491 & 1 & & & & & & & \\
\hline (3) December SL & .084 & .168 & 1 & & & & & & \\
\hline (4) February LNK & .786 & .368 & .098 & 1 & & & & & \\
\hline (5) February PA & .283 & .405 & .301 & .292 & 1 & & & & \\
\hline (6) February SK & .342 & .393 & .274 & .278 & .102 & 1 & & & \\
\hline (7) May LNK & .635 & .297 & .089 & .776 & .229 & .209 & 1 & & \\
\hline (8) May PA & .509 & .615 & .174 & .491 & .500 & .343 & .432 & 1 & \\
\hline (9) May SK & .640 & .483 & .191 & .630 & .334 & .366 & .556 & .662 & 1 \\
\hline
\end{tabular}

Note. $\mathrm{LNK}=$ letter naming knowledge. $\mathrm{PA}=$ phonological awareness. $\mathrm{SK}=$ spelling knowledge. All correlations were significant at $p<.001$.

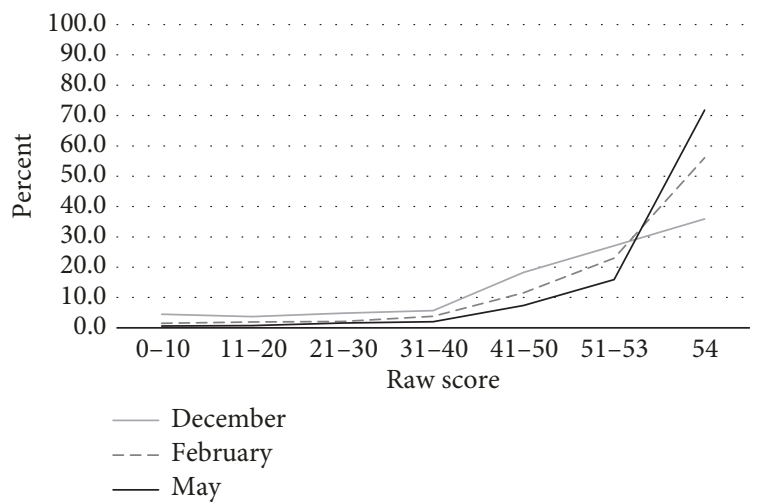

FIGURE 1: Percentage of students by number correct for letter naming knowledge (LNK) for December, February, and May.

May the mean of 51.9 resulted in $71.8 \%$ of students knowing all letters. Phonological awareness (PA), the second variable under consideration, was measured with a ceiling equal to 55. Examination of the PA means (Figure 2) reveals that in December $15.5 \%$ of students had scored 50 or higher. By February $24.8 \%$ of students had reached criterion and by May this percentage increased to $48.0 \%$. Attainment for spelling knowledge (Figure 3) (range of 0 to 30) shows that in December $11.5 \%$ of students had attained a score of 24 or higher. By February $20.1 \%$ of students score 24 or higher, while three months later in May, $72.1 \%$ of all students scored 24 or higher. Table 2 shows the bivariate correlations. Of note is the strengthening of the relationship between LNK and spelling knowledge across the three months from .084 in December to .278 in February and .556 in May. Also of interest is the increase in correlation between PA and spelling knowledge from .168 in December, to .102 in February, to .662 in May. Figure 1 shows the growth of the three measured variables across the three measurement periods.

3.1. Research Question One. Our first research question asks how do letter identification knowledge (LNK), phonological awareness (PA), and spelling knowledge (SK) emerge across the latter half of kindergarten. Figure 4 plots the changes in the measured variables across the three measurement periods. To answer this question we conducted a repeated

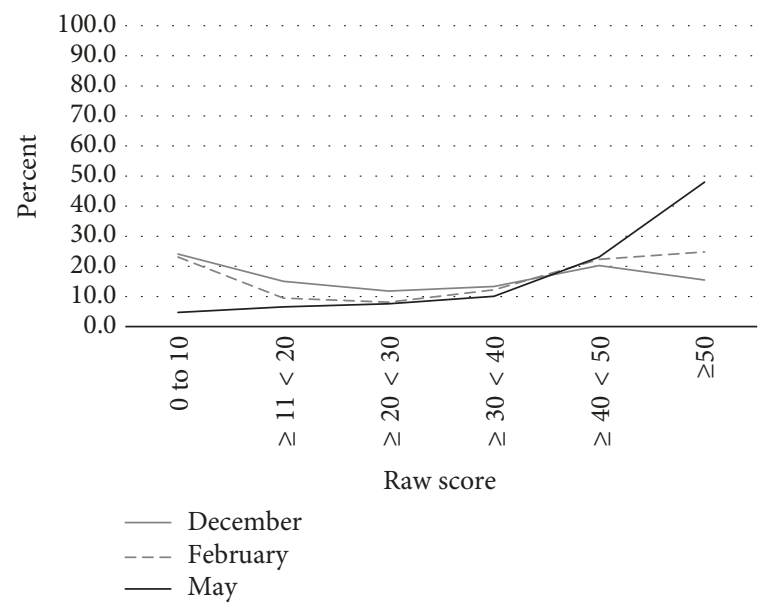

FIgURe 2: Percentage of students by number correct for phonological awareness (PA) for December, February, and May.

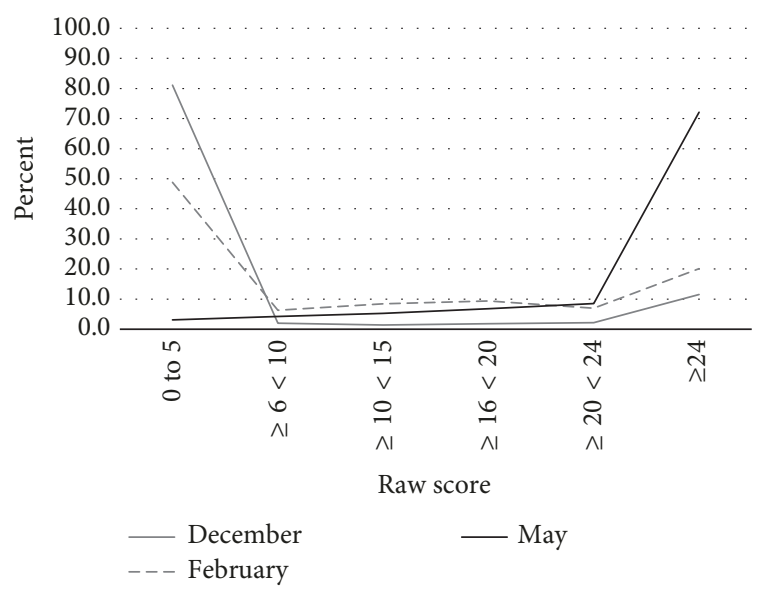

FIgURE 3: Percentage of students by number correct for spelling knowledge (SK) for December, February, and May.

measures analysis for time (December, February, and May) for each of the three variables. An assumption of repeated measures when three or more conditions are present is that the variances for each should be similar. Each of our three variables resulted in significant Mauchly's test indicating the 
TABLE 3: Multivariate and univariate analysis of variance for reading measures.

\begin{tabular}{|c|c|c|c|c|c|}
\hline \multirow{2}{*}{ Source } & \multicolumn{2}{|c|}{ Multivariate } & \multicolumn{3}{|c|}{ Univariate } \\
\hline & $\mathrm{df}$ & $F$ (Cohen's $d$ ) & LNK $^{\mathrm{a}}$ (Cohen's $d$ ) & $\mathrm{PA}^{\mathrm{b}}$ (Cohen's $d$ ) & SK $^{\mathrm{c}}$ (Cohen's $d$ ) \\
\hline December to May & 6,8394 & $883.51^{* * *}(.92)$ & $522.55^{* * *}(.57)$ & $774.42^{* * *}(.86)$ & $3454.22^{* * *}(1.81)$ \\
\hline December to February $^{\mathrm{d}}$ & & & $491.75^{* * *}(.68)$ & $47.18^{* * *}(.21)$ & $507.73^{* * *}(.70)$ \\
\hline February to May ${ }^{\mathrm{d}}$ & & & $196.06^{* * *}(.43)$ & $863.07^{* * *}(.91)$ & $3508.42^{* * *}(1.83)$ \\
\hline
\end{tabular}

Note. Multivariate $F$ ratios were generated using Pillai's statistic. LNK = letter naming knowledge; PA = phonological awareness; SK = spelling knowledge; ${ }^{\mathrm{a}} \mathrm{df}=1.43,24566.50 .{ }^{\mathrm{b}} \mathrm{df}=1.73,144963.62 .{ }^{\mathrm{c}} \mathrm{df}=1.90,244861.22 .{ }^{\mathrm{d}} \mathrm{df}=1,2099 .{ }^{* * *} p<.001$.

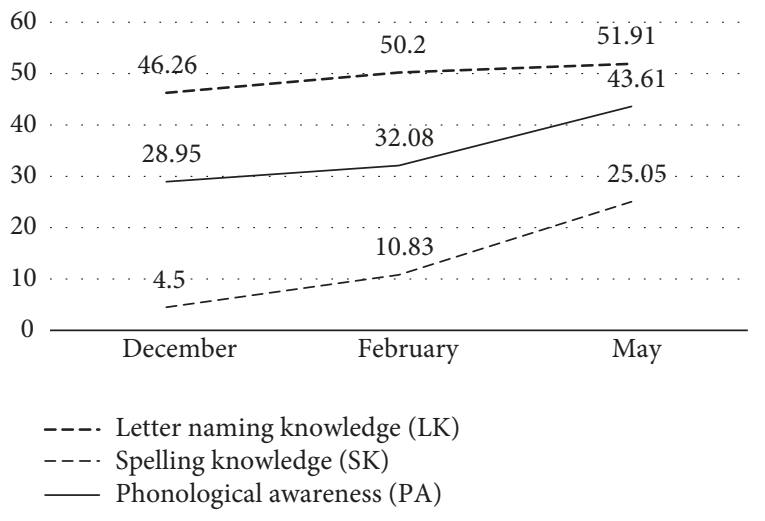

FIGURE 4: Changes in the measured variables by measurement period.

assumption of sphericity had been violated: LNK, $\chi^{2}(2)=$ $1130.48, p<.001$; PA, $\chi^{2}(2)=201.99, p<.001$; and SK, $\chi^{2}(2)=48.03, p<.001$. To correct for sphericity violations degrees of freedom are adjusted using Greenhouse-Geisser estimates. Using Pillai's Trace, multivariate results (Table 3) show a significant main effect in the measured variables over time: $V=.774, F(6,8394)=883.51, p<.001$, and $d=.92$. Univariate results show statistically significant increases for LNK: $F(1.43,24566.50)=522.55, p<.001, d=.57$; for PA, $F(1.73,144963.62)=774.42, p<.001$, and $d=.86$; and SK, $F(1.90,244861.22)=3454.22, p<.001, d=1.81$.

Statistically significant growth in LNK, PA, and SK was found between the December and February and February and May time periods. For the December to February period, $\mathrm{LNK}=F(1,2099)=491.75, p<.001$, and $d=.68 ; \mathrm{PA}=$ $F(1,2099)=47.18, p<.001$, and $d=.21$; and SK $=F(1,2099)$ $=507.73, p<.001$, and $d=1.83$. For February to May time period, $\mathrm{LNK}=F(1,2099)=196.06, p<.001$, and $d=.43$; $\mathrm{PA}=F(1,2099)=863.07, p<.001$, and $d=.91$; and $\mathrm{SK}=$ $F(1,2099)=3508.42, p<.001$, and $d=1.83$.

3.2. Research Question Two. The second question of interest is the extent to which letter naming knowledge (LNK) and phonological awareness (PA) predict spelling knowledge (SN) in kindergarten children. To answer this question, we conducted a series of hierarchical regression analyses where we regressed spelling knowledge onto letter naming knowledge and phonological awareness. To gain insight into the predictive value of these variables over time, this same model was constructed for each of the three measurement periods. Table 4 displays the results for each measurement period.

For December only phonological awareness was a significant predictor of spelling knowledge, explaining $2.8 \%$ of the variance, $t=6.78$ and $p<.001$. For the February time period letter naming knowledge becomes the sole significant predictor of spelling knowledge, explaining $7.7 \%$ of the variance, $t=12.41$ and $p<.001$. By May both letter naming knowledge and phonological awareness are statistically significant predictors of spelling knowledge. Letter naming knowledge accounts for $31 \%$ of the variance in spelling knowledge, $t=20.30$ and $p<.001$, while phonological awareness predicts $21.8 \%$ of the variance in spelling knowledge, $t=31.65$ and $p<.001$. Together letter naming knowledge and phonological awareness explain $52.7 \%$ of the variance in spelling knowledge. Also of interest are the changes in the standardized betas across time. In December, the beta for letter naming knowledge equals .001 (nonsignificant) while phonological awareness equals .168 $(p<.001)$. In February the standardized beta for letter naming knowledge equals $.270(p<.001)$ while phonological awareness (beta $=.027)$ is a nonsignificant predictor. In May, the standardized beta for letter naming knowledge equals $.332(p<.001)$ while phonological awareness equals .518 $(p<.001)$.

\section{Discussion}

The goal of this study was to investigate the emergence of early literacy skills associated with instruction, across a large urban school district in the latter part of kindergarten. In pursuit of this we measured the growth of letter naming knowledge (LNK), phonological awareness (PA), and spelling knowledge (SK) of 2,100 kindergarten students, across three time periods, who attended schools where students typically struggle with reading acquisition. We found first that the acquisition of LNK came slowly, with just over 33\% of students knowing all 54 letters by December. By February $56.1 \%$ of students knew all letters, and by the end of May just under $72 \%$ of students knew every letter. This meant that over $28 \%$ of end-of-kindergarten students could not name all letters of the alphabet in upper- and lowercase form by the end of kindergarten, a critical benchmark for reading acquisition.

Phonological awareness would be expected to emerge more slowly than letter naming knowledge and our results supported this. At the end of December, $15.5 \%$ of students 
TABLE 4: Hierarchical regression results when regressing spelling knowledge onto letter identification knowledge and phonological awareness.

\begin{tabular}{|c|c|c|c|c|c|c|}
\hline & $B$ & SE $B$ & $B$ & $\Delta R^{2}$ & $R^{2}$ & $t$ \\
\hline \multicolumn{7}{|l|}{ December $(n=2,100)$} \\
\hline \multicolumn{7}{|l|}{ Variable 1} \\
\hline Constant & 1.590 & .787 & & & & $2.02^{*}$ \\
\hline Letter naming knowledge & .063 & .016 & .084 & & .007 & $3.85^{* * *}$ \\
\hline \multicolumn{7}{|l|}{ Variable 2} \\
\hline Constant & 1.846 & .779 & & & & $2.37^{*}$ \\
\hline Letter naming knowledge & .001 & .019 & .001 & & .007 & 0.04 \\
\hline Phonological awareness & .091 & .013 & .168 & .021 & .028 & $6.78^{* * *}$ \\
\hline \multicolumn{7}{|l|}{ February $(n=2,100)$} \\
\hline \multicolumn{7}{|l|}{ Variable 1} \\
\hline Constant & -6.870 & 1.352 & & & & $-5.08^{* * *}$ \\
\hline Letter naming knowledge & .352 & .027 & .278 & & .077 & $13.277^{* * *}$ \\
\hline \multicolumn{7}{|l|}{ Variable 2} \\
\hline Constant & -6.88 & 1.352 & & & & $-5.094^{* *}$ \\
\hline Letter naming knowledge & .342 & .028 & .270 & & .077 & $12.41^{* * *}$ \\
\hline Phonological awareness & .016 & .012 & .027 & .001 & .077 & .211 \\
\hline \multicolumn{7}{|l|}{$\operatorname{May}(n=2,100)$} \\
\hline \multicolumn{7}{|l|}{ Variable 1} \\
\hline Constant & -4.784 & .962 & & & & $-4.97^{* * *}$ \\
\hline Letter naming knowledge & .574 & .018 & .556 & & .310 & $31.18^{* * *}$ \\
\hline \multicolumn{7}{|l|}{ Variable 2} \\
\hline Constant & -3.797 & .796 & & & & $-4.77^{* *}$ \\
\hline Letter naming knowledge & .343 & .017 & .332 & & .310 & $20.30^{* * *}$ \\
\hline Phonological awareness & .253 & .008 & .518 & .218 & .527 & $31.65^{* * *}$ \\
\hline
\end{tabular}

Note. ${ }^{*} p<.05 ;{ }^{* *} p<.01 ;{ }^{* * *} p<.001$.

had scored a 50 out of 55 on the PA assessment. In February, this percentage increased to $24.8 \%$ and by May $48.0 \%$ of students scored 50 or higher. In December $11.5 \%$ of students scored 24 out of 30 on the spelling knowledge assessment, while in February the percentage nearly doubled to $20.1 \%$. May revealed dramatic growth where $72.1 \%$ of students had scored 24 out of 30 . Our repeated measures analysis revealed large growth for LNK between December and February $(d=$ .68) while PA grew slowly $(d=.21)$ and SK showed huge growth of nearly two standard deviations $(d=1.83)$. Between February and May LNK continued to grow at a moderate pace $(d=.43)$, PA grew at a very large rate $(d=.91)$, and SK grew again at a rate equal to December to May rate $(d=1.83)$. In summary, our results suggest first that letter naming knowledge continues to grow through the end of the kindergarten year. Second, PA emerges slowly until February and then grows very quickly through the end of the year. Third, SK showed large growth through the February and May measurement periods. These results suggest that LNK, PA, and SK share a symbiotic relationship where growth in one aids growth in the others. For example, Henderson and Beers [34] suggest that as the child's ability to discriminate phonemes in words becomes developed, their ability to identify consonants increases. This phenomenon is seen in our results where increasing PA scores led to large increases in SK, suggesting students were relying on their phonemic awareness skills to correctly identify the beginning and ending consonants in the SK assessment.

Our second research question investigated the extent to which LNK and PA predicted SK. We found that in December LNK was a nonsignificant predictor of SK while PA accounted for $2.8 \%$ of the variance in spelling knowledge. While this is a small amount of variance that may be driven by our large sample size, it does suggest an emerging relationship between PA and SK. In February, phonological awareness was no longer a significant predictor of spelling knowledge while letter naming predicted $7.7 \%$ of the variance. While this is a curious result, the percentage of students able to correctly name all letters increased by over $50 \%$ to $56.1 \%$ of all students and may be driving the results. While the percentage of students achieving PA improved by $60 \%$, the overall percentage was just less than $25 \%$. This suggests a tipping point in the data where LNK becomes a stronger predictor than PA as LNK increases. Between February and May LN grew by $28 \%$ to a point where nearly $72 \%$ of students could correctly name all letters, while PA grew by almost $94 \%$ to a point where $48 \%$ of students attained a score $\geq 50$ out of 55. Our regression results showed that both LNK and PA were significant predictors of SK, accounting for $31.0 \%$ and $21.8 \%$ of the variance, respectively, and explaining a total of $52.7 \%$ of the variance. In May both LN and PA were significant predictors of SK, with the betas equal to .332 and 
.518 , respectively. Our results align with those of Ouellette and Sénéchal [26] who also found that LNK and PA predicted SK. The theoretical framework informing this study is drawn from the verbal efficiency and lexical quality hypotheses [3-6] and the connectionist model as proposed by Seidenberg and McClelland [7]. Our results support the primary hypotheses of these two theories that as reading subskills increase in efficiency, reading outcomes improve.

4.1. Study Limitations. The results of this study should be carefully interpreted with the following limitations in mind. The sample of students was not randomly sampled and represents many who come from backgrounds of poverty. It could be that a different student who was randomly drawn might exhibit very different growth trajectories on the measured variables. Also, a population not from atrisk backgrounds may also show very different development patterns from those seen in our study. While we described the teachers participating in the study it is not appropriate to attribute any differences in student growth to instruction as there is no control group of teachers to which a comparison can be made. The results of this study reflect our study sample and should not be generalized to other districts or populations of students.

4.2. Future Research. This study measured the emergence of several critical reading subskills related to effective reading. The value of this study is that the data on 2,100 kindergarten students was gathered along three time points within a large, diverse school district with students attending 63 urban schools. Future research efforts could implement a longitudinal approach that follows students across first grade and possibly beyond. Other studies could employ additional measures to capture other subskills known to be important to reading such as rapid letter naming, working memory, and language factors. Of interest to future research could be further investigation to more precisely define critical tipping points in letter identification and phonological awareness critical to spelling knowledge.

\section{Conflicts of Interest}

The authors declare that they have no conflicts of interest.

\section{Acknowledgments}

The open access publishing fees for this article have been covered by the Texas A\&M University Open Access to Knowledge Fund (OAKFund), supported by the University Libraries and the Office of the Vice President for Research.

\section{References}

[1] G. J. Duncan, C. J. Dowsett, A. Claessens et al., "School Readiness and Later Achievement," Developmental Psychology, vol. 43, no. 6, pp. 1428-1446, 2007.

[2] NCES, National Center for Education Statistics, 2015., Results from the 2013 NAEP Reading and Mathematics Assessments (NCES 2015-046), U.S. Department of Education,, National
Center for Education Statistics, Washington, DC, USA, 2015, http://nces.ed.gov/pubsearch.

[3] S. S. Conrad, "Reading Ability. Charles A. Perfetti. New York: Oxford University Press, 1985. Pp. 282.," Applied Psycholinguistics, vol. 7, no. 02, p. 178, 1986.

[4] C. A. Perfetti, "Verbal efficiency in reading ability," in Reading research: Advances in theory and practice, M. Daneman, G. E. MacKinnon, and T. G. Waller, Eds., pp. 109-143, Academic Press, New York, 1988.

[5] C. Perfetti, "Reading ability: Lexical quality to comprehension," Scientific Studies of Reading, vol. 11, no. 4, pp. 357-383, 2007.

[6] C. A. Perfetti and L. Hart, "The lexical quality hypothesis," in Precursors of functional literacy, L. Verhoevfen, C. Elbro, and P. Reitsma, Eds., pp. 189-213, John Benjamins, Philadelphia, PA, 2002.

[7] M. S. Seidenberg and J. L. McClelland, "A Distributed, developmental model of word recognition and naming," Psychological Review, vol. 96, no. 4, pp. 523-568, 1989.

[8] National Research Council, "Testing, teaching, and learning: a guide for states and school districts. Committee on title I testing and assessment," in Board on Testing and Assessment, Commission on Behavioral and Social Sciences and Education, R. F. Elmore and R. Rothman, Eds., National Academy Press, Washington, DC, USA, 1999.

[9] B. Foorman, N. Beyler, K. Borradaile, M. Coyne, C. A. Denton, and J. Dimino, "Foundational skills to support reading for understanding," in in kindergarten through 3rd grade (NCEE 2016-4008), National Center for, Washington, DC, 2016, http://whatworks.ed.gov.

[10] C. Schatschneider, J. M. Fletcher, D. Francis, C. D. Carlson, and B. Foorman, "Kindergaren prediction of reading skills: A longitudinal comparative analysis," Journal of Educational Psychology, vol. 96, pp. 265-282, 2004.

[11] M. Adams, Beginning to read: Thinking and learning about print, MIT Press, Cambridge, MA, 1990.

[12] E. J. Gibson and H. Levin, The psychology of reading, MA, Cambridge, 1975.

[13] M. A. Evans, M. Bell, D. Shaw, S. Moretti, and J. Page, "Letter names, letter sounds and phonological awareness: An examination of kindergarten children across letters and of letters across children," Reading and Writing, vol. 19, no. 9, pp. 959-989, 2006.

[14] C. F. Nodine and F. G. Simmons, "Processing distinctive features in the differentiation of letterlike symbols," Journal of Experimental Psychology, vol. 103, no. 1, pp. 21-28, 1974.

[15] K. Rayner, A. Pollatsek, J. Ashby, and Clifton. Jr. C., Psychology of reading, Psychology Press, New York, 2nd edition, 2012.

[16] D. L. Share, "Phonological recoding and self-teaching: sine qua non of reading acquisition," Cognition, vol. 55, no. 2, pp. 151-218, 1995.

[17] P. Worden and W. Boettcher, "Young childrens acquisition of alphabetic knowledge," Journal of Reading Behavior, vol. 22, pp. 277-295, 1990.

[18] B. Byrne, The foundation of literacy: The childs acquisition of the alphabetic principle, Psychology Press, Hove, UK, 1998.

[19] M. Stuart and M. Coltheart, "Does reading develop in a sequence of stages?" Cognition, vol. 30, no. 2, pp. 139-181, 1988.

[20] F. R. Vellutino, J. M. Fletcher, M. J. Snowling, and D. M. Scanlon, "Specific reading disability (dyslexia): What have we learned in the past four decades?" Journal of Child Psychology and Psychiatry, vol. 45, no. 1, pp. 321-363, 2004. 
[21] D. J. Walsh, G. G. Price, and M. G. Gillingham, "The critical but transitory importance of letter naming," Reading Research Quarterly, vol. 23, pp. 108-122, 1988.

[22] N. A. Badian, "A Validation of the Role of Preschool Phonological and Orthographic Skills in the Prediction of Reading," Journal of Learning Disabilities, vol. 31, no. 5, pp. 472-481, 1998.

[23] K. E. Stanovich, A. E. Cunningham, and B. B. Cramer, "Assessing phonological awareness in kindergarten children: Issues of task comparability," Journal of Experimental Child Psychology, vol. 38, no. 2, pp. 175-190, 1984.

[24] B. Blachman, "Relationship of rapid naming ability and language analysis skill to kindergarten and first-grade reading achievement," Journal of Educational Psychology, vol. 76, pp. 610-622, 1984.

[25] L. C. Ehri, "Grapheme-phoneme knowledge is essential for learning to read words in English. In," in Word recognition in beginning literacy, J. L. Metsala and L. C. Ehri, Eds., p. 40, Erlbaum, Mahwah, NJ, 1998.

[26] G. Ouellette and M. Sénéchal, "Invented spelling in kindergarten as a predictor of reading and spelling in grade 1: A new pathway to literacy, or just the same road, kess known?" Developmental Psychology, vol. 53, no. 1, pp. 77-88, 2017.

[27] G. Ouellette, M. Sénéchal, and A. Haley, "Guiding childrens invented spellings: A gateway into literacy learning," Journal of Experimental Education, vol. 81, no. 2, pp. 261-279, 2013.

[28] C. Read, "Pre-School Children's Knowledge of English Phonology," Harvard Educational Review, vol. 41, no. 1, pp. 1-4, 1971.

[29] F. R. Vellutino and D. M. Scanlon, "Phonological coding, phonological awareness, and reading ability: Evidence from a longitudinal and experimental study," Merrill-Palmer Quarterly, vol. 33, pp. 321-363, 1987.

[30] R. H. Felton, F. B. Wood, I. S. Brown, S. K. Campbell, and M. R. Harter, "Separate verbal memory and naming deficits in attention deficit disorder and reading disability," Brain and Language, vol. 31, no. 1, pp. 171-184, 1987.

[31] M. Wolf and M. Obregón, "Early naming deficits, developmental dyslexia, and a specific deficit hypothesis," Brain and Language, vol. 42, no. 3, pp. 219-247, 1992.

[32] D. Share, A. Jorm, R. MacLean, and R. Matthews, "Sources of individual differences in reading achievement," Journal of Educational Psychology, vol. 76, pp. 1309-1324, 1984.

[33] J. R. Gentry, "An analysis of developmental spelling in GNYS AT WRK," The Reading Teacher, vol. 36, pp. 192-200, 1982.

[34] E. H. Henderson and J. W. Beers, "Developmental and cognitive aspects of learning to spell: A reflection of word knowledge," in Proceedings of the International Reading Association, Newark, DE, 1980.

[35] U. Goswami, "Phonological and lexical processes," in Handbook of reading research, M. L. Kamil, P. B. Mosenthal, P. D. Pearson, and R. Barr, Eds., vol. 3, Erlbaum, Mahwah, New Jersey, 2000.

[36] T. L. Harris and R. E. Hodges, "The literacy dictionary: The vocabulary of reading and writing," Newark, New Jersey, 1995.

[37] H. K. Yopp, "The Validity and Reliability of Phonemic Awareness Tests," Reading Research Quarterly, vol. 23, no. 2, pp. 159177, 1988.

[38] T. C. Papadopoulos, P. Kendeou, and G. Spanoudis, "Investigating the Factor Structure and Measurement Invariance of Phonological Abilities in a Sufficiently Transparent Language," Journal of Educational Psychology, vol. 104, no. 2, pp. 321-336, 2012.
[39] C. Schatschneider, D. J. Francis, B. R. Foorman, J. M. Fletcher, and P. Mehta, "The dimensionality of phonological awareness: An application of item response theory," Journal of Educational Psychology, vol. 91, no. 3, pp. 439-449, 1999.

[40] S. A. Stahl and B. A. Murray, "Defining Phonological Awareness and Its Relationship to Early Reading," Journal of Educational Psychology, vol. 86, no. 2, pp. 221-234, 1994.

[41] J. K. Torgesen, R. K. Wagner, and C. A. Rashotte, "Longitudinal studies of phonological processing and reading.," Journal of Learning Disabilities, vol. 27, no. 5, pp. 276-287, 1994.

[42] C. E. Snow and M. S. Burns, "Preventing reading difficulties in youngchildren," in Preventing reading difficulties in youngchildren, C. E. Snow, M. S. Burns, and P. Griffin, Eds., National Academy Press, Washington, DC, 1998.

[43] J. S. Chall, Stages of reading development, McGraw-Hill, New York, 1983.

[44] G. Ouellette and M. Sénéchal, "Pathways to literacy: A study of invented spelling and its role in learning to read," Child Development, vol. 79, no. 4, pp. 899-913, 2008.

[45] B. A. Blachman, "Phonological awareness," in Common core state standards for English, Language Arts Appendix A, M. L. Kamil and P. B. Mosenthal, Eds., National Governors Association and Council of Chief State School Officers, 2000.

[46] D. M. Tangel and B. A. Blachman, "Effect of phoneme awareness instruction on the invented spelling of first-grade children: a one-year follow-up," Journal of Reading Behavior, vol. 27, no. 2, pp. 153-185, 1995.

[47] J. R. Gentry and J. W. Gillet, Teaching kids to spell, Heinemann, Portsmouth, NH, 1993.

[48] S. Templeton, "Theory, nature, and pedagogy of higher-order orthographic development in older students," in Development of orthographic knowledge and the foundations of literacy: A memorial festschrift, S. Templeton and D. R. Bear, Eds., Erlbaum Associates, Hillsdale, NJ, 1992.

[49] L. C. Ehri, "How English orthography influences phonological knowledge as children learn to read and spell," in Literacy and Language Analysis, J. R. Scales, Ed., pp. 21-43, Lawrence Erlbaum Associates, Hillsdale, NJ, USA, 1993.

[50] K. Ganske, "The developmental spelling analysis: a measure of orthographic knowledge," Educational Assessment, vol. 6, no. 1, pp. 41-70, 2010.

[51] R. Treiman, Beginning to Spell, Oxford University Press, NY, USA, 1993.

[52] S. Wilde, You Kan Red This!: Spelling and Punctuation for Whole Language Classrooms, K-6, Heinemann publisher, Portsmouth, NH, USA, 1991.

[53] C. A. Perfetti, "Why inferences might be restricted," Discourse Processes, vol. 16, pp. 181-192, 1993.

[54] L. C. Ehri, "Learning to read and learning to spell are one and the same, almost," in Learning to Spell: Research Theory and Practice across Languages, C. A. Perfetti, L. Rieban, and M. Fayol, Eds., pp. 237-260, Lawrence Erlbaum Associates, Mahwah, NJ, USA, 1997.

[55] L. C. Ehri, "Sources of difficulty in learning to spell and read," in Advances in Developmental and Behavioral Pediatrics, M. L. Wolraich and D. Routh, Eds., vol. 7, pp. 121-195, JAI, Greenwich, CT, USA, 1986.

[56] L. C. Ehri, "Learning to read and spell words," Journal of Reading Behavior, vol. 19, no. 1, pp. 5-31, 1987.

[57] U. Frith, "Beneath the surface of developmental dyslexia," in Surface Dyslexia, K. E. Patterson, J. C. Marshall, and M. 
Coltheart, Eds., pp. 301-330, Routledge \& Kegan Paul, London, 1985.

[58] A. A. Roman, J. R. Kirby, R. K. Parrila, L. Wade-Woolley, and S. H. Deacon, "Toward a comprehensive view of the skills involved in word reading in grades 4, 6, and 8," Journal of Experimental Child Psychology, vol. 102, pp. 96-113, 2009.

[59] S. A. Stage and R. K. Wagner, "Development of young children's phonological and orthographic knowledge as revealed by their spellings," Developmental Psychology, vol. 28, no. 2, pp. 287-296, 1992.

[60] E. H. Henderson, Learning to Read and Spell: The Child's Knowledge of Words, Northern Illinois Press, DeKalb, IL, USA, 1981.

[61] J. Zutell, "An integrated view of word knowledge: correlational studies of the relationships among spelling, reading, and conceptual development," in Development of Orthographic Knowledge and the Foundations of Literacy: A Memorial Festschrift for Edmund H. Henderson, S. Templeton and D. R. Bear, Eds., pp. 213-230, Routledge, NY, USA, 1992.

[62] P. Seymour, M. Aro, and J. Erskine, "Foundation literacy acquisition in European orthographies," British Journal of Psychology, vol. 94, pp. 143-174, 2003.

[63] E. W. Ball and B. A. Blachman, "Does phoneme awareness training in kindergarten make a difference in early word recognition and developmental spelling?" Reading Research Quarterly, vol. 26, no. 1, pp. 49-66, 1991.

[64] A.-C. Kjeldsen, A. Kärnä, P. Niemi, Å. Olofsson, and K. Witting, "Gains From Training in Phonological Awareness in Kindergarten Predict Reading Comprehension in Grade 9," Scientific Studies of Reading, vol. 18, no. 6, pp. 452-467, 2014.

[65] C. Hulme, C. Bowyer-Crane, J. M. Carroll, F. J. Duff, and M. J. Snowling, "The Causal Role of Phoneme Awareness and Letter-Sound Knowledge in Learning to Read: Combining Intervention Studies With Mediation Analyses," Psychological Science, vol. 23, no. 6, pp. 572-577, 2012.

[66] M. Caravolas, A. Lervåg, P. Mousikou et al., "Common Patterns of Prediction of Literacy Development in Different Alphabetic Orthographies," Psychological Science, vol. 23, no. 6, pp. 678686, 2012.

[67] R. B. Cooter Jr, E. S. Flynt, and K. S. Cooter, The Comprehensive reading inventory: Assessment of reading skills in English and Spanish, Pearson,.

[68] K. Ganske, Word journeys: Assessment-guided phonic, spelling, and vocabulary instruction, The Guilford Press, New York, 2nd edition, 2014. 


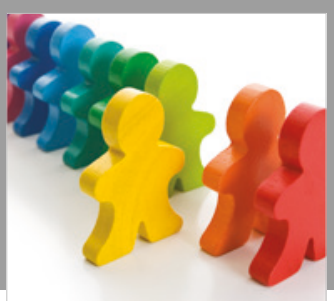

Autism

Research and Treatment
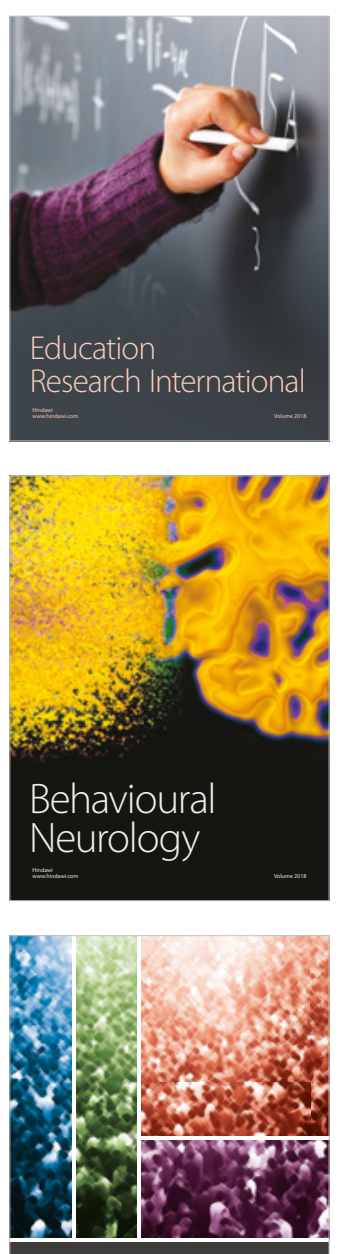

International Journal of

Population Research

$\underline{-m}$

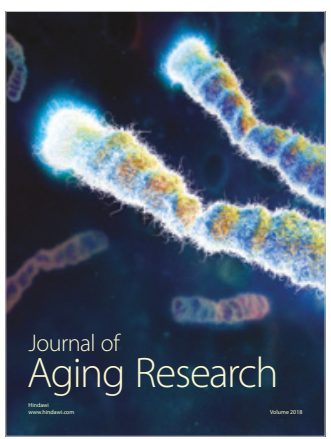

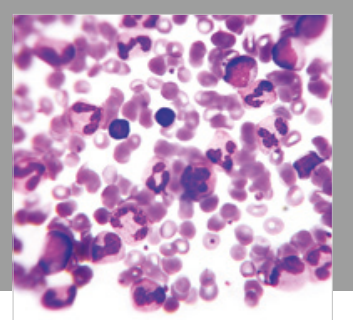

Pathology

Research International$$
=
$$

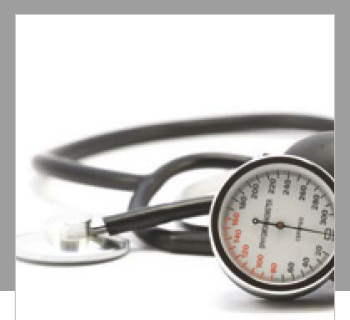

Nursing

Research and Practice

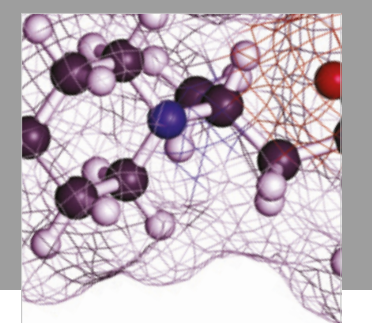

Pain

Research and Management

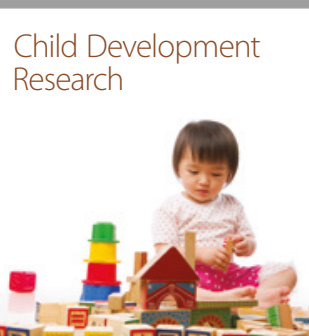

बाD

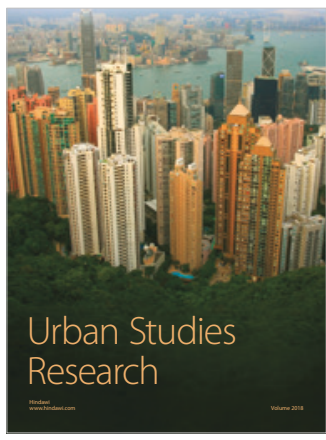

\section{Hindawi}

Submit your manuscripts at

www.hindawi.com
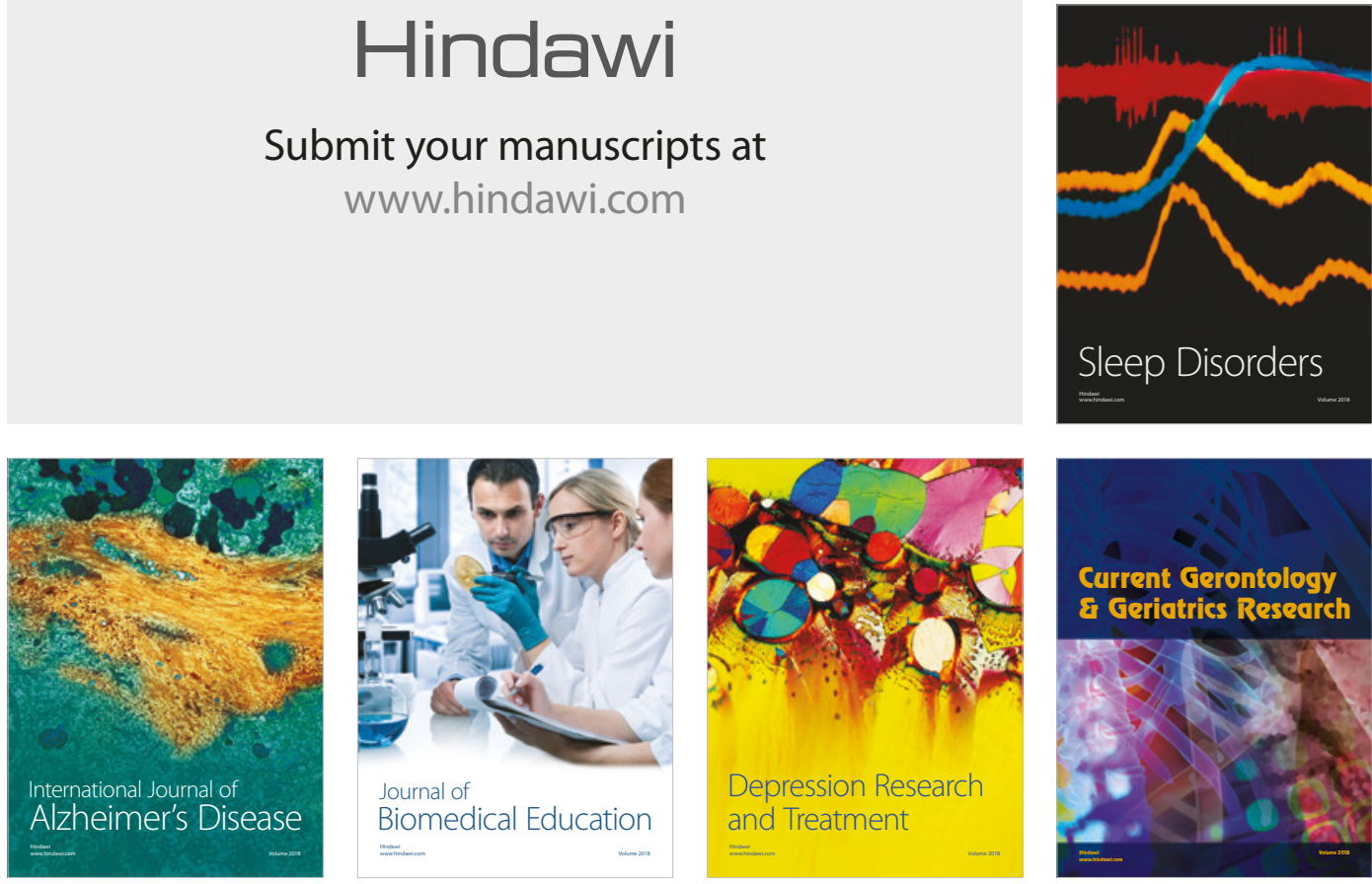

Journal of

Biomedical Education

$=$

smman

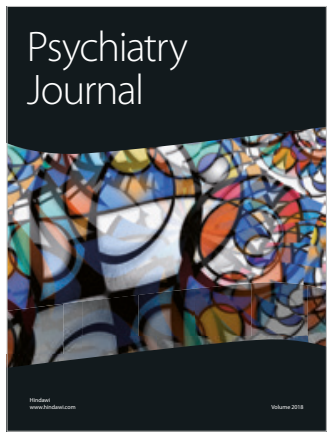

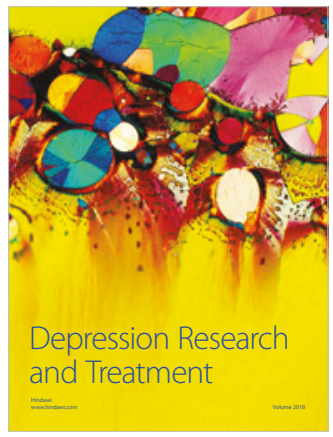
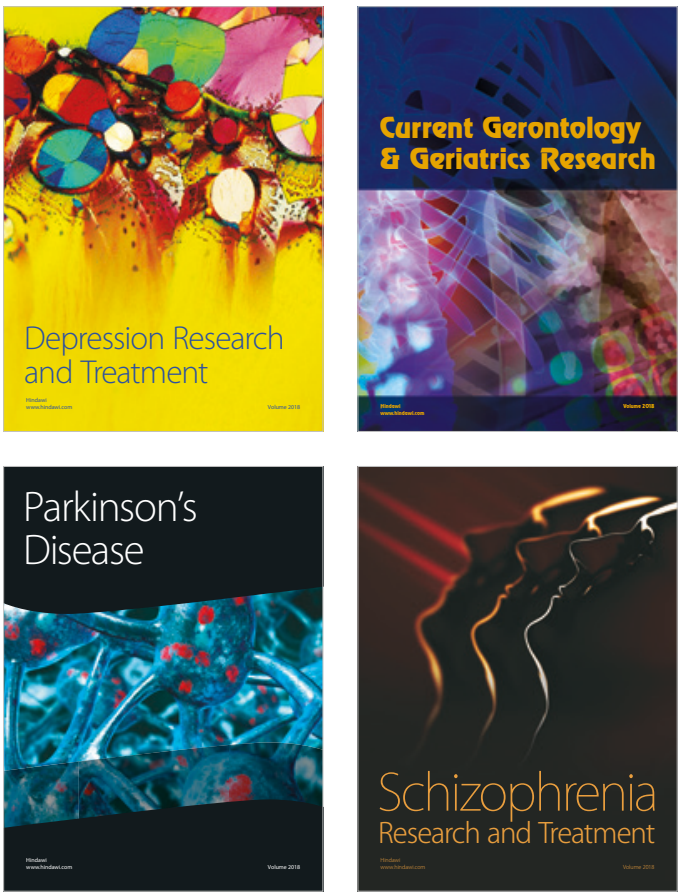